\title{
Kidney transplantation in Type 1 (insulin-dependent) diabetic patients
}

\section{Early glomerulopathy}

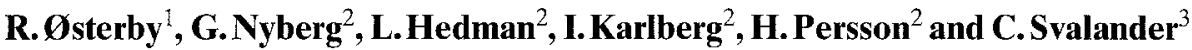 \\ ${ }^{1}$ Institute for Experimental Clinical Research, Institute of Pathology, Århus Kommunehospital, Denmark, ${ }^{2}$ Transplant Unit and \\ 3 Institute of Pathology, Sahlgrenska Hospital, Göteborg, Sweden
}

\begin{abstract}
Summary. The development of diabetic glomerulopathy in kidneys transplanted to diabetic patients was estimated in transplant biopsies and evaluated in relation to suspected clinical risk factors for diabetic nephropathy. Surgical biopsies were taken at baseline and at 24-36 months post-transplantation in 16 Type 1 (insulin-dependent) diabetic patients and 8 non-diabetic control subjects with a glomerular filtration rate more than $30 \mathrm{ml} \cdot \mathrm{min}^{-1}$ at follow-up. Immunosuppressive therapy included cyclosporine in all but one case. Stereological methods were used to assess basement membrane thickness, volume fraction of mesangium per glomerulus, and volume fraction of matrix per mesangium. The volume fraction of interstitial tissue per cortex was estimated by light microscopy. After 2 years the basement membrane thickness had increased by $55 \mathrm{~nm}$ (SD $58 \mathrm{~nm}$ ) in the diabetic group. This change was significantly different from that of $2 \mathrm{~nm}(\mathrm{SD} 37 \mathrm{~nm})$ in control subjects $(p=0.02)$. Mesangial volume fraction increased significantly by 0.04 (SD 0.03) in diabetic patients, and this change was significantly different from that of -0.01 (SD 0.04) in non-diabetic patients $(p=0.009)$. No change was detectable in the matrix ex-
\end{abstract}

pressed as fraction of mesangial volume. An increase in interstitial volume fraction from baseline to 2 years was observed, but was significant only in the diabetic group $(p=0.04)$. The changes in structural parameters did not correlate with mean values during follow-up of glycated haemoglobin or estimated protein intake, nor was any pattern discernible in the relationship to graft tissue types. The observed increase in basement membrane thickness corresponds to that observed in native kidneys during the first years of diabetes, whereas an increase in mesangial volume fraction - using a different protocol - was not observed in the early phase of the natural development. Absence of correlation with the various risk factors may reflect an irrelevance of these variables within the current range, or their influence may be offset by stronger mechanisms in the transplant situation, and therefore does not appear in this relatively small series.

Key words: Kidney transplants, diabetic glomerulopathy, basement membrane thickness, mesangial volume fraction, interstitial fibrosis, cyclosporine, stereology.
Transplantation is a mode of renal replacement therapy which has a high success rate in diabetic patients with endstage renal failure [1-4]. One early concern regarding renal transplantation in diabetic patients was the possibility of a recurrence of diabetic glomerulopathy in the transplanted organs. A specific quality of the transplanted kidney is that it is single, and therefore, according to the hyperfiltration hypothesis $[5,6]$ might be more prone than native kidneys to developing glomerulopathy.

Previous transplant biopsy studies [7-10] have indicated that within the first 10 years after transplantation the structural changes are modest and unlikely to have any immediate clinical significance. However, histopathological changes develop during the clinically silent phase and analysis of the relationship between structural changes and clinical variables in this early stage may elucidate factors that significantly influence the process.

The previous studies on development of diabetic glomerulopathy in transplanted kidneys have covered a wide time-range from transplantation to biopsy, and very few biopsies have been performed in the earliest phase, when the first sign of glomerulopathy appears. This stage might be optimal for studies to clarify the pathogenetic mechanisms.

The report from Minneapolis in 1983 [7] of biopsies taken after 2 years was carefully designed and included baseline biopsies taken at transplantation as well as biopsies from non-diabetic control patients who had undergone kidney transplantation. Quantitative electron microscopy was, however, performed in only four diabetic subjects. We have carried out a similar study, comprising 
Table 1. Clinical data for kidney transplanted Type 1 (insulin-dependent) diabetic patients

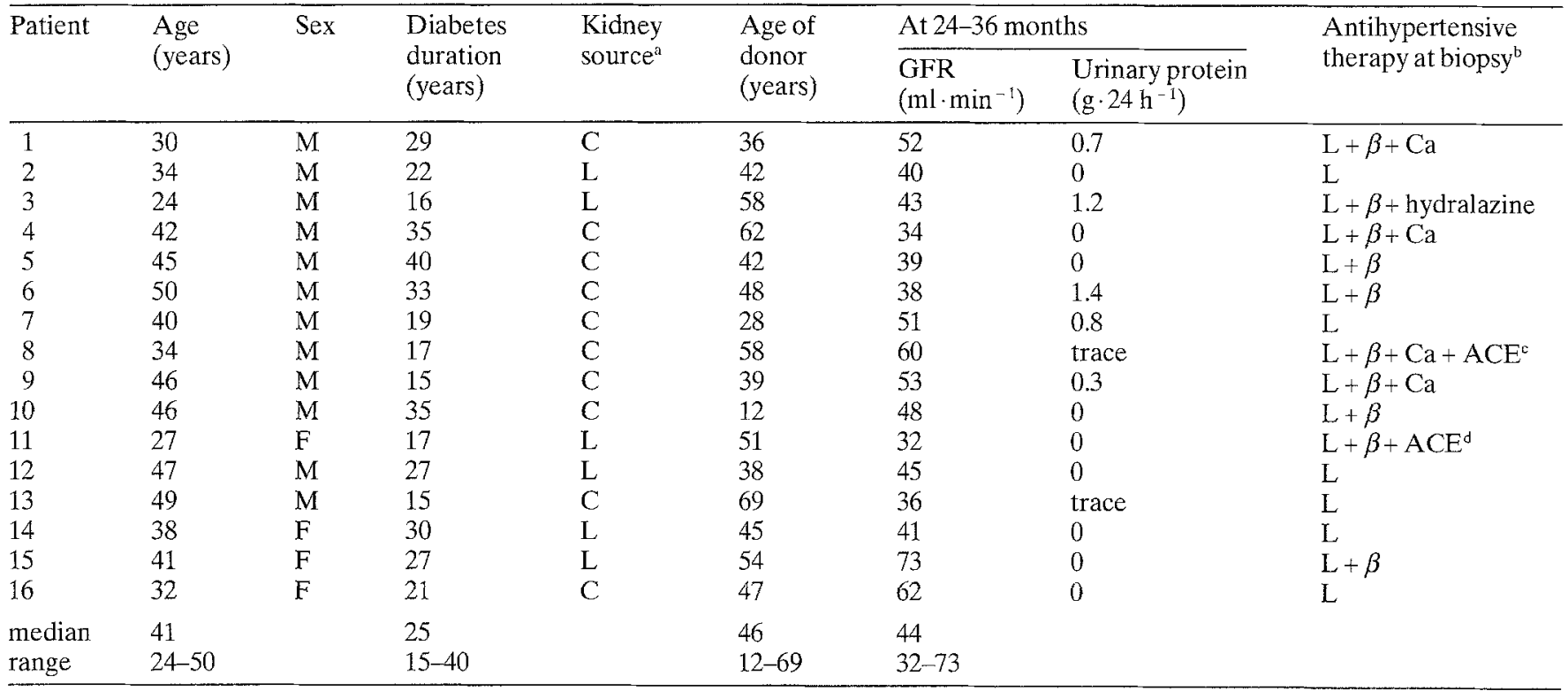

${ }^{a} \mathrm{~L}=$ Living donor, $\mathrm{C}=$ Cadaveric donor ${ }^{\circ} \mathrm{L}=$ Loop diureticum, $\beta=\beta_{1}$ blocking agent, $\mathrm{Ca}=$ calcium blocker, $\mathrm{ACE}=$ angiotensin converting enzyme inhibitor; ${ }^{c}$ duration of therapy 31 months; ${ }^{\unlhd}$ duration of therapy 7 months.

$\mathrm{GFR}=$ glomerular filtration rate

Table 2. Clinical data for kidney transplanted control patients

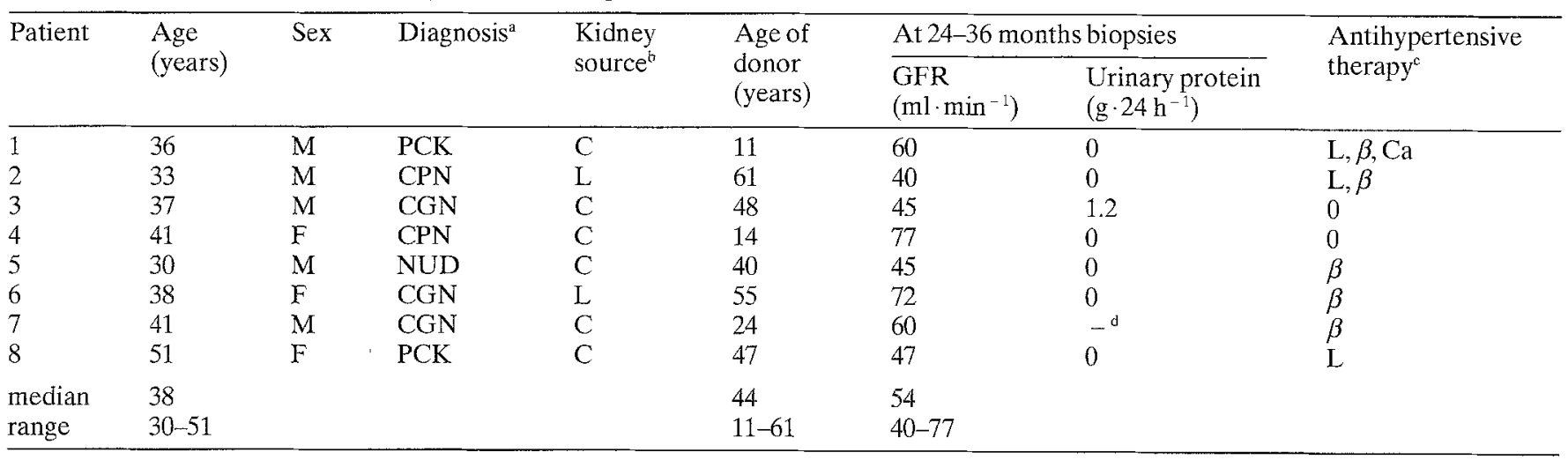

a $\mathrm{PCK}=$ Polycystic kidney disease, $\mathrm{CGN}=$ Chronic glomerulonephritis, $\mathrm{CPN}=$ Chronic pyelonephritis, NUD $=$ Unknown; ${ }^{\mathrm{b}} \mathrm{L}=\mathrm{Living}$ donor, $\mathrm{C}=$ cadaveric donor; ${ }^{\mathrm{c}} \mathrm{L}=$ Loop diuretic, $\beta=\beta_{1}$ blocking agent, $\mathrm{Ca}=$ calcium blocker; ${ }^{\mathrm{d}}$ Low grade, not quantified

larger groups of patients, in whom a close clinical followup was also performed.

\section{Subjects and methods}

\section{Subjects}

According to the protocol established for this study in 1983, baseline biopsies should be taken from all kidneys transplanted to Type 1 diabetic patients, and to selected control patients. Repeat biopsies should be performed after 6 and 24 months. The present series is a group of 16 consecutive diabetic patients in whom biopsies were taken at transplantation and at 24-36 months follow-up. Clinical data are given in Table 1. Patients were accepted for this series only if their glomerular filtration rate (GFR) exceeded $30 \mathrm{ml} \cdot \mathrm{min}^{-1}$ at the time of the last biopsy. Control subjects were selected preferentially as recipients of one kidney from a cadaveric donor, when the other kidney was transplanted to a diabetic patient. Repeat biopsies were obtained from eight control subjects (Table 2). Only two of the baseline pairs underwent follow-up biopsies (diabetic patient 6 control subject 3 , and diabetic patient 16 - control subject 8 ). Reasons for drop-out were graft function loss or-insufficiency, intercurrent disease or the patient's decision not to participate. The study was approved by the local Ethics Committee.

\section{Clinical programme and laboratory methods}

The immunosuppressive protocol included cyclosporine $A$ in all patients except diabetic patient 15 who received an HLA-identical graft and was treated with only azathioprine and prednisolone. Blood concentration of cyclosporine was monitored using a radioimmunoassay method with a polyclonal antibody. Trough levels were similar in diabetic patients and control subjects, $331 \pm 188$ vs $336 \pm 106$ (mean $\pm S D) \mu g /$ at the time of the $2-3$ year biopsy.

Following transplantation, 17 diabetic patients injected insulin twice per day, most often as a combination of rapid and medium long-acting insulin, six patients injected three or four times a day. During follow-up one patient changed from two injections to the 
Table 3. Suspected risk factors in Type 1 (insulin-dependent) diabetic patients who underwent kidney transplant biopsies at 2-3 years posttransplant



a corrected to 24 months

$\mathrm{BMT}=$ basement membrane thickness; $\mathrm{V}_{\mathrm{V}}(\mathrm{mes} / \mathrm{glom})=$ volume fraction of mesangium in the glomerulus

subcutaneous insulin pump, and six patients from two or three to four daily injections. Metabolic control was evaluated by multiple $\mathrm{HbA}_{1 \mathrm{c}}$ analysis, 4-21 times per patient (median 12 times), excluding the first 3 months, when erythropoesis is very active. All determinations were made at the Department of Clinical Chemistry, Sahlgrenska Hospital, using ion exchange chromatography on Mono S (Pharmacia Fine Chemicals AB, Uppsala, Sweden). The reference interval in young adults being $3.7-5.1 \%$. The frequency of determinations depended on whether the patients attended our out-patient clinic or were seen here only for scheduled follow-up at $6,12,18$ and 24 months post-transplant (see Table 3 ).

Blood pressure was closely monitored in all the diabetic patients and control subjects. Hypertension was treated aggressively and diastolic values above $90 \mathrm{~mm} \mathrm{Hg}$ in the supine position were not accepted unless orthostatic blood pressure fall (in some diabetic patients) prevented treatment. Antihypertensive drugs were used at the time of the last biopsy in all diabetic patients and all but two control subjects (Tables 1 and 2). Any angiotensin converting enzyme (ACE) inhibitor medication during follow-up is listed separately. None of the control subjects received such treatment.



Fig. 1. Semithin plastic section as used for the estimate of interstital volume fraction. Three such sections were used per biopsy. The section shown is from the baseline biopsy from control subject 6 , illustrating fibrosis in a biopsy from a living donor, with normal renal function tests. The magnification is $75 \times$
Protein intake was estimated at 12 or 24 months in most diabetic patients by dietary history interview, covering habits over the past year and evaluated as previously described [11] (see Table 3).

Glomerular filtration rate (GFR) was determined at regular intervals, including all biopsy occasions, as the plasma concentration slope following a single bolus injection of ${ }^{51} \mathrm{CrEDTA}$ [12]. Tables 1 and 2 show the individual values.

Urinary protein excretion was determined by the Tscuchiya method [13] on $24 \mathrm{~h}$ samples (Tables 1 and 2).

\section{Biopsies}

All biopsies were cortical wedge specimens, obtained in the operating room, the kidney surface being exposed for inspection. The baseline biopsies were taken about 30 min after revascularization. The tissue was mailed in $2.5 \%$ glutaraldehyde fixative in $0.1 \mathrm{~mol} / \mathrm{l} \mathrm{ca}$ codylate buffer, $\mathrm{pH} 7.4$, to the laboratory in Arhus, Denmark where preparation for light- and electron microscopy was completed, using paraffin and Vestopal as embedding media. Paraffin sections were used for estimation of glomerular volume and frequency of glomerular occlusion (results to be published).

Light microscopy. From the plastic embedded blocks semithin sections $(1 \mu \mathrm{m})$ were cut and stained with toluidine blue for the identification and unbiased sampling of glomerular profiles for electron microscopy [14]. The sections cut immediately before the trimming around the sampled glomerular profile (Fig. 1) were used for estimation of interstitium as proportion of cortical tissue. This was done with a drawing tube attached to the microscope, enabling the projection of a point-grid to the visual fields. Points hitting the interstitium, defined as the space outside tubular epithelium, Bowman's capsule and large vessels (i.e., including capillaries and cells), and total number of points hitting the cortex (excluding renal corpuscles) were counted to provide the volume fraction of interstitium per cortex (minus renal corpuscles): $\mathrm{Vv}$ (interst/cortex). The counting was done by one person, unaware of the source of the biopsy, at $142 \times$ magnification with a point distance corresponding to $105 \mu \mathrm{m}$.

Electron microscopy. The three glomerular profiles were photographed at magnification of $2400 \times$ to produce photomontages of 


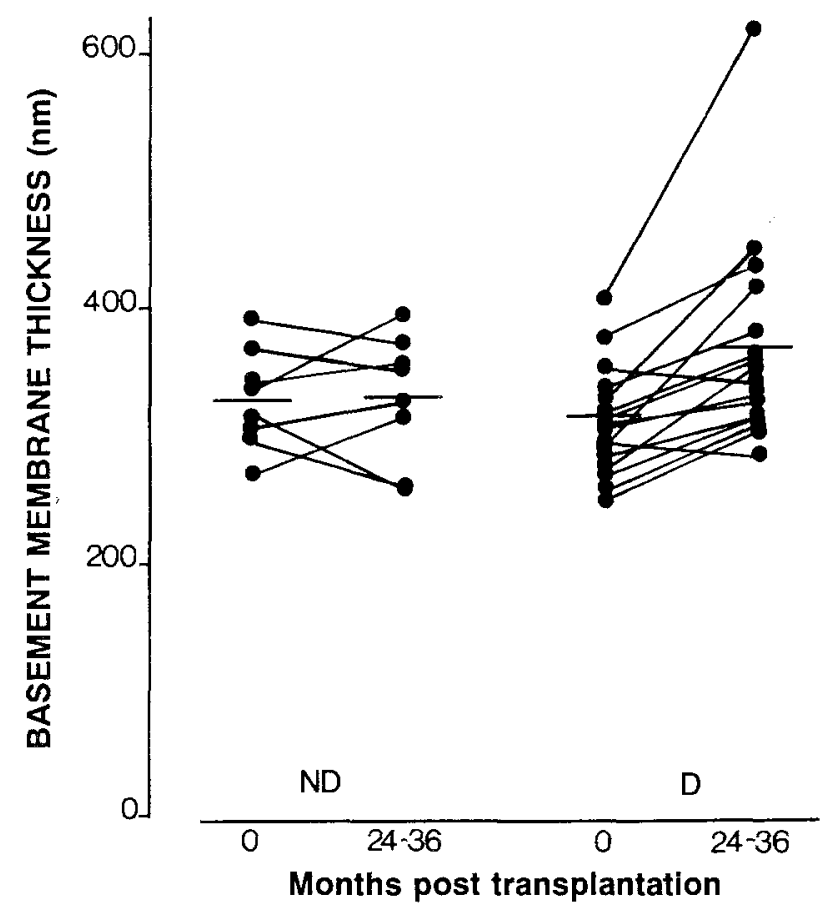

Fig. 2. Glomerular basement membrane thickness in sequential biopsies from eight non-diabetic (left) and 16 diabetic patients (right). The group of diabetic patients shows an increase over the 2-year period ( $p=0.0011)$, significantly different from the change in control subjects $(p=0.023)$

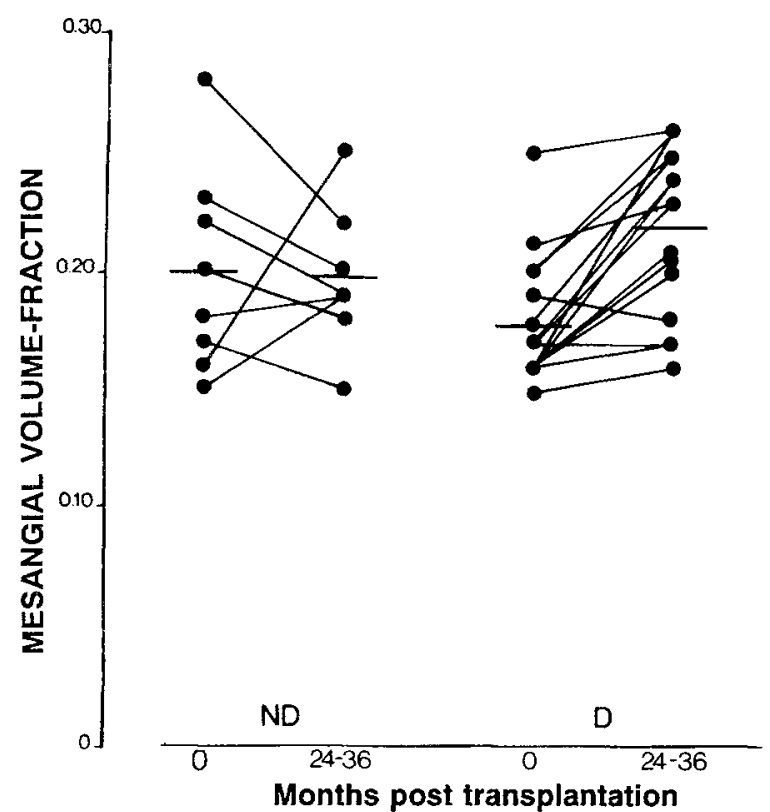

Fig.3. Estimates of mesangial volume fraction, i. e, the fraction of the glomerulus occupied by the solid mesangial space, made from biopsies from eight non-diabetic (left) and 16 diabetic (right) patients. The increase in the diabetic patients is significant $(p=0.0006)$, and is different from the change in the group of control subjects $(p=0.009)$

the entire profiles. The montages were used for the estimation of mesangial regions as fraction of the total glomerulus, defined as the circumscribed, minimal convex polygon [15]. For this purpose a 1:8 point-grid was used with a distance between coarse points corresponding to $22 \mu \mathrm{m}$. The fine points were used for hits on mesangium. Another set of micrographs, with an independent position on the in- dividual profiles, was photographed at $10000 \times$ magnification. The set covered approximately $45 \%$ of the total profile and was used for the estimation of basement membrane thickness by the orthogonal intercept method [16], and volume fraction of matrix in the mesangium, Vv(matrix/mes), using an integral test system with different sets of points: 1:1:2 for glomerular tuft, mesangium and matrix, respectively. The distance between coarse points corresponded to $5 \mu \mathrm{m}$.

\section{Statistical analysis}

The change over time in follow-up biopsies was tested by paired $t$-tests. Differences between groups were tested by unpaired $t$ on delta-values and correlations expressed by Spearman's correlation coefficient, $r$. Group values are presented in the tables with mean, or median, and SD or coefficient of variation $(\mathrm{CV})=\mathrm{SD} /$ mean.

\section{Results}

Although age of donor and the proportion of living to cadaveric donors differed between diabetic patients and control subjects the baseline biopsies showed no significant differences in the three parameters expressing diabetic glomerulopathy: basement membrane (BM) thickness was $328 \mathrm{~nm}$ (CV 0.12) for control subjects and $312 \mathrm{~nm}$ (CV 0.14) for diabetic patients. Mesangial volume fraction, $V_{v}$ (mes/glom), was $0.20(\mathrm{CV} 0.22)$ vs $0.18(0.15)$, and $V_{V}$ (matrix/mes) 0.54 (CV 0.16) vs 0.49 (CV 0.18). Interstitial volume fraction, $\mathrm{V}_{\mathrm{V}}($ interst/cortex $)$, in the areas of the kidney used for electron microscopy was of the same order in the two groups, and showed considerable variation between biopsies: $0.27(\mathrm{CV} 0.34)$ and $0.29(\mathrm{CV}$ 0.32 ), respectively.

Biopsies obtained after 6 months in a subset of patients showed no significant changes in the glomerulopathy parameters.

The duration from transplantation to the last biopsy spanned a period from 23 to 36 months, on average 25.8 months in diabetic patients (SD 3.8) and 28.6 months (SD 6.1) in control subjects. The structural parameters estimated in the last biopsies were 'normalized' to a 24-month standard, assuming a linear rate of development from baseline to end-point.

In the two year biopsies basement membrane thickness had not increased in the control group $(2 \pm 37 \mathrm{~nm}$, mean $\pm S D$ ), whereas the increase of $55 \pm 58 \mathrm{~nm}$ in the diabetic group was statistically significant whether the entire group was considered $(p=0.0019)$, or patient 1 was omitted from the calculation $(p=0.0011)$. Individual data are shown in Table 3, and illustrated in Figure 2. Comparison of delta-values in diabetic patients vs control subjects was also statistically significant $(p=0.023)$.

The diabetic group also showed a significant increase in mesangial volume fraction by $0.04 \pm 0.03$ (mean \pm SD), $p=0.0006$, to a mean value for the group of 0.21 (CV 0.15$)$ (Table 3 and Fig. 3). No significant change was observed in the control subjects $(-0.01 \pm 0.04)$. The difference between control subjects and diabetic patients was statistically significant $(p=0.009)$. The change in $\mathrm{Vv}(\mathrm{mes} / \mathrm{glom})$ observed in individual diabetic patients showed no signifi- 


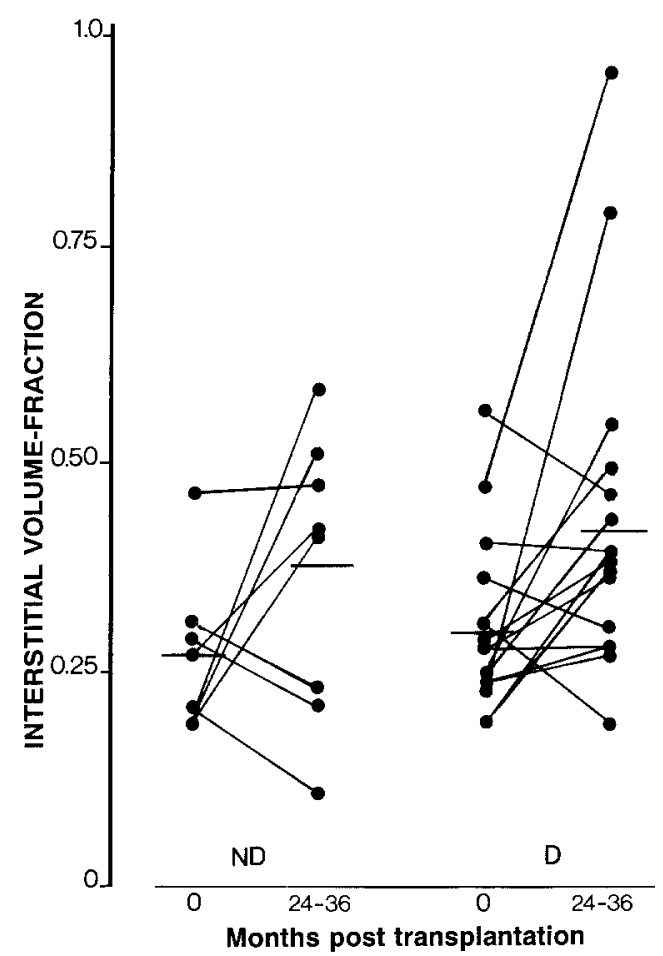

Fig.4. Volume fraction of interstitial tissue in cortex, excluding renal corpuscles, estimated in the areas used for quantitative electron microscopy. The eight non-diabetic patients are shown (left) and the diabetic patients (right). The increase over time was statistically significant only in the diabetic group $(p=0.04)$

cant correlation to the change in basement membrane thickness (Table 3).

The volume fraction of matrix in the mesangium did not change significantly in either group, $-0.03 \pm 0.12$ in control subjects and $+0.06 \pm 0.14$ in diabetic patients, and the difference in delta-values between groups was not statistically significant.

The interstitial volume fraction increased on average by 0.10 (SD 0.19) in the control group, and by 0.13 (SD 0.22 ) in the diabetic group (Fig. 4). The change reached statistical significance only in diabetic patients $(p=0.04)$. Current $\mathrm{V}_{\mathrm{V}}$ (interst/cortex) at 2 years did not correlate with basement membrane thickness or $V_{V}(\mathrm{mes} / \mathrm{glom})$ in the diabetic group, whereas variation in $\mathrm{V}_{\mathrm{v}}$ (interst/cortex) could account for $32 \%$ of the variation in $\mathrm{V}_{\mathrm{V}}(\mathrm{mes} / \mathrm{glom})$ in control subjects, $(r=0.57)$.

There was no correlation between structural findings and any of the clinical presumed risk factors recorded, $\mathrm{HbA}_{1 c}$, dietary protein intake or tissue type.

\section{Discussion}

The aim of this study was to follow the development of diabetic glomerulopathy in the initial phase after a renal transplantation to diabetic patients. Diabetic glomerulopathy is characterized by three structural parameters, basement membrane thickness, volume fraction of mesangium per glomerulus and volume fraction of matrix per mesangium. Each of these parameters is a continuous variable, showing a certain range in control subjects $[17$,
18], due to the combined effect of a true biological variation, and the errors in the estimate consequent to sampling and measurements. Therefore, to detect subtle changes in the early phase consideration of the precision of the parameters in question, as well as determination of the baseline values are important [19]. The inclusion of cadaveric donors in whom clinical information is sometimes sparse, broadens the range of baseline values [18].

Previous studies of glomerular structure in the native kidney from diabetic patients have shown an early increase in basement membrane thickness [19]. The expansion of mesangial regions is a very important aspect of diabetic glomerulopathy with respect to the late demise in glomerular function [20,21]. This change however, is demonstrable only in fairly advanced stages in the native kidney [20,22], whereas the present series of transplanted kidneys showed an increase in both parameters after only 2 years. The basement membrane thickening corresponded well with findings in native kidneys [19], albeit with a much larger variation within the group, as well as with those of the Minneapolis series of transplanted diabetic patients [7]. The renal transplant series published from Minneapolis did not show an increase in mesangial volume fraction in groups of diabetic patients with 1 7 years' duration $[7,10]$. This conforms, however, with the fact that the estimates in diabetic patients after 2 years are still completely within the normal range, so that the positive outcome depended on the paired comparison. An earlier detection in the present series compared with the native kidneys could relate to the larger series and the use of three rather than two random profiles. Yet, a large variation remained between the three individual profiles, and the question remains, if the observed increase in mesangial volume fraction is in fact an expression of incipient diabetic glomerulopathy, or alternatively, the finding is a random outcome - irrespective of statistical significance in a parameter with a low precision. Changes of similar magnitude were observed in the control group, where they seemed to represent a "regression towards the mean". The lack of correlation between the increase in $\mathrm{V}_{\mathrm{v}}(\mathrm{mes} / \mathrm{glom})$ and basement membrane thickening in this series is noteworthy.

Another important point to take into account in studying changes in these parameters is that none of them is 'specific' for diabetic glomerulopathy, and the transplanted kidney is exposed to many factors that may influence glomerular structures, independent of the diabetic state. Changes in the large vessels may present a main problem, whether due to rejection phenomena, cyclosporine toxicity and effects of other drugs, or pre-existing nephrosclerosis in the transplanted kidney. A relative vascular insufficiency could influence glomerular structural integrity directly or by an interaction via an increase in the interstitial space. The more dramatic graft reactions were excluded in the present series, since only patients with GFR in excess of $30 \mathrm{ml} \cdot \mathrm{min}^{-1} \cdot 1.73 \mathrm{~m}^{-2}$ body surface were accepted in the study. Even this limit, however, allows the inclusion of biopsies which were damaged at the outset or became so during follow-up.

The cyclosporine nephrotoxicity has rightly been a matter of great concern. Myers et al. [23] have described 
hyalinization of arterioles and mesangial expansion as an effect of cyclosporine treatment in cardiac transplant recipients. This shows the necessity of having a control group of non-diabetic renal transplant recipients. The control group in our series, although treated with cyclosporine, did not show increase in mesangial volume fraction over the 2-year period. The dosage of cyclosporine taken by our patients, reflected as blood cyclosporine concentration was, however, much lower than in the cardiac transplanted patients. This is probably of great importance for the development of cyclosporine nephrotoxicity [24].

An increase in interstitial volume fraction has been described as one of the frequently encountered consequences of cyclosporine treatment $[23,25]$. Our estimate concentrated upon the areas within the biopsies immediately adjacent to the glomeruli studied by electron microscopy in order to test a possible correlation with the structural quantities in those particular glomeruli. The estimates do not necessarily represent the overall fibrosis in the individual kidneys, since one characteristic of the interstitial changes is the patchy localization. In our control group a positive correlation was obtained between the $V_{V}$ (interst/cortex) and the $\mathrm{V}_{\mathrm{v}}$ (mes/glom) at 2 years. In our study we were careful to sample any glomerular profile, irrespective of its structural appearance, to get unbiased estimates valid for the population of open glomeruli. Only totally occluded glomeruli had to be excluded from the analysis, since the structural definitions are lost in such corpuscles, and quantitations are therefore not possible.

There is now accumulating evidence that the development of late diabetic complications is related to the degree of diabetic control $[26,27]$. It may then seem surprising that $\mathrm{HbA}_{1 \mathrm{c}}$ values recorded during follow-up were not related to the basement membrane thickening. One possible explanation is that the range of $\mathrm{HbA}_{1 \mathrm{c}}$ values was high and rather narrow. An alternative explanation would be that the transplanted kidneys differ in their sensibility to hyperglycaemia. Although we could not identify such sensibility on the basis of HLA-tissue type, this remains a possibility. Mauer et al. [9] have suggested that intrinsic factors in the transplanted kidney may play a major role.

As for protein intake, the suggested harmful effect has not been clearly proven, although there is experimental evidence from diabetic rats [31] and clinical data suggesting a beneficial effect of protein restriction on the expression of the marker of early nephropathy, elevated urinary albumin excretion. In the transplanted kidney model no correlation was seen between protein intake and the development of diabetic glomerulopathy, in spite of the fact that protein intake ranged from very low to very high values. For reasons mentioned above, this does not, however, exclude the possibility of high protein intake as a risk factor in the long run.

The finding of a significant increase in basement membrane thickness also in the transplant model demonstrated that the pathogenic mechanisms of diabetic glomerulopathy are active also in this setting.

Acknowledgements. The skillful technical assistance of Ms. K. Gerlach, Ms. L. Nielsen and Ms. B. Saugbjerg is gratefully acknowledged.
The project has been supported by grants from: Helen and Einar BjørnovsFoundation, The Danish Diabetes Association, The Danish Medical Research Council, Bernhard og Marie Klein's Legat, Ruth I.E. König-Petersens Foundation, Nordic Insulin Foundation, NOVO Foundation, Århus University Research Foundation.

\section{References}

1. Larsson O (1985) Kidney transplantation in diabetic renal failure. Scand J Urol Nephrol [Suppl] 95: 1-84

2. Jacobson SH, Fryd D, Sutherland DER, Kjellstrand CM (1988) Treatment of the diabetic patient with end-stage renal failure. Diab Metab Rev 4: 191-200

3. Frei U, Schorn T, Bunzendahl H (1989) Kidney transplantation in diabetic nephropathy. In: Heidland A, Koch KM, Heidbreder E (eds) Diabetes and the kidney. Contrib Nephrol Karger, Basel, pp 199-208

4. Fauchald P, Albrechtsen D, Lindholm A, Persson H, Frødin L, Persson N, Flatmark A (1990) Results of renal transplantation in diabetic nephropathy. Transplant Proc 22: 1431

5. Hostetter TH, Rennke HG, Brenner BM (1982) The case for intrarenal hypertension in the initiation and progession of diabetic and other glomerulopathies. Am J Med 72:375-380

6. Zatz R, Brenner BM (1986) Pathogenesis of diabetic microangiopathy. The hemodynamic view. Am J Med 80: 443-453

7. Mauer SM, Steffes MW, Connett J, Najarian JS, Sutherland DER, Barbosa J (1983) The development of lesions in the glomerular basement membrane and mesangium after transplantation of normal kidneys to diabetic patients. Diabetes 32 : 948-952

8. Bohman S-O, Wilczek H, Jaremko G, Tydén G (1988) Recurrence of diabetic nephropathy in renal transplants. In: Mogensen CE (ed) The kidney and hypertension in diabetes mellitus. Nijhoff, Boston, pp 395-402

9. Mauer SM, Goetz FC, McHugh LE, Sutherland DER, Barbosa J, Najarian JS, Steffes MW (1989) Long-term study of normal kidneys transplanted into patients with Type I diabetes. Diabetes 38: $516-523$

10. Bilous RW, Mauer SM, Sutherland DER, Najarian JS, Goetz FC, Steffes MW (1989) The effects of pancreas transplantation on the glomerular structure of renal allografts in patients with insulin-dependent diabetes. N Engl J Med 321: 80-85

11. Nyberg G, Nordén G, Attman PO, Aurell M, Uddebom G, Arvidsson Lenner R, Isaksson B (1987) Diabetic nephropathy. Is dietary protein harmful? J Diab Compl 1: 37-40

12. Brøchner-Mortensen J, Giese J, Rossing N (1969) Renal inulin clearance versus total plasma clearance of ${ }^{51} \mathrm{CrEDTA}$. Scand $\mathbf{J}$ Clin Lab Invest 23: 301-305

13. Lehman J (1947) Proteinbestämning i serum respektive plasma och urin. Nord Med 33: 338-345

14. Østerby R, Gundersen HJG (1978) Sampling problems in the kidney. In: Miles RE, Serra J (eds) Lecture notes in biomathematics, Vol. 23. Springer, Berlin Heidelberg New York, pp 185191

15. Østerby R, Parving H-H, Nyberg G, Hommel E, Jørgensen HE, Løkkegaard H, Svalander C (1988) A strong correlation between glomerular filtration rate and filtration surface in diabetic nephropathy. Diabetologia 31: 265-270

16. Jensen EB, Gundersen HJG, $\emptyset_{\text {sterby R (1979) Determination }}$ of membrane thickness distribution from orthogonal intercepts. J Microsc 115: 19-33

17. Steffes MW, Barbosa J, Basgen JM, Sutherland DER, Najarian JS, Mauer SM (1983) Quantitative glomerular morphology of the normal human kidney. Lab Invest 49: 82-86

18. Østerby R, Nyberg G, Andersson G, Frisk B (1988) Glomerular structural quantities in baseline biopsies from cadaveric donor kidney paris. APMIS [Suppl] 4: 130-136

19. Østerby R (1975) Early phases in the development of diabetic glomerulopathy. A quantitative electron microscopic study. Acta Med Scand [Suppl] 574 (Thesis) 
20. Mauer SM, Steffes MW, Ellis EN, Sutherland DER, Brown DM, GoetzFC (1984) Structural-functional relationships in diabetic nephropathy. J Clin Invest 74: 1143-1155

21. Steffes MW, Østerby R, Chavers B, Mauer SM (1989) Mesangial expansion as a central mechanism for loss of kidney function in diabetic patients. Diabetes 38: 1077-1081

22. Østerby R, Gundersen HJG, Nyberg G, Aurell M (1987) Advanced diabetic glomerulopathy. Quantitative structural characterization of nonoccluded glomeruli. Diabetes 36: 612-619

23. Myers BD, Sibley R, Newton L et al. (1988) The long-term course of cyclosporine-associated chronic nephropathy. Kidney Int 33:590-600

24. Stiller CR, Opelz G (1991) Should cyclosporine be continued indefinitely? Transplant Proc 23: 36-40

25. Bergstrand A, Bohman S-O, Farnsworth A et al. (1985) Renal histopathology in kidney transplant recipients immunosuppressed with cyclosporin A: results of an international workshop. Clin Nephrol 24: 107-119

26. Feldt-Rasmussen B, Mathiesen ER, Jensen T, Lauritzen T, Deckert T (1991) Effect of improved metabolic control on loss of kidney function in Type 1 (insulin-dependent) diabetic patients: an update of the Steno studies. Diabetologia 34: 164-170
27. Dahl-Jørgensen K, Hanssen KF, Kierulf P, Bjøro T, Sandvik L, Aagenæs $\varnothing$ (1988) Reduction of urinary albumin excretion after 4 years of continuous subcutaneous insulin infusion in insulindependent diabetes mellitus. The Oslo study. Acta Endocrinol (Copenh) 117: 19-25

28. Zatz R, Meyer TW, Rennke HG, Brenner BM (1985) Predominance of hemodynamic rather than metabolic factors in the pathogenesis of diabetic glomerulopathy. Proc Natl Acad Sci USA 82: 5963-5967

Received: 14 January 1991

and in revised form: 21 May 1991

Dr. R. Østerby

Electron Microscopy Laboratory

Institute of Pathology

Kommunehospitalet

DK-8000 Århus C

Denmark 